\title{
DESIGN OF A COMPRESSION STRUCTURE WITH INNER RIBS USING FORCE DENSITY METHOD \& TOPOLOGICAL MAPPING
}

\author{
Manuel Alejandro Fernández Ruiz* \\ Department of Structural Mechanics, University of Granada, Spain \\ Luisa Maria Gil-Martin \\ Department of Structural Mechanics, University of Granada, Spain
}

Compression-only structures can be modelled as pin-jointed networks with all the members in compression. The final shape of the network can be computed using the Force Density Method (FDM) together with Topological Mapping (TM), introducing the self-weight iteratively until the equilibrium is found. One of the input parameters of FDM is the force-length ratio q of each member of the network. Members with a high q carry a higher level of loads, working as ribs of the structure. The designer defines the proper distribution of the ribs in the network, resulting in aesthetical final shapes. Here, a two-storey compression structure with inner ribs has been designed using TM-FDM.

Key words: Compression structures, Force Density Method, Topological Mapping, Form-finding

\section{INTRODUCTION}

The Force Density Method (FDM) first introduced by Schek [01-03] is a method used to solve the form-finding problem of pin-jointed networks. Pin-jointed networks are composed by nodes or joints and members. These members can be in tension (cables) or in compression (rods). The main input of FDM is the force-length ratio or force density $q$. The equilibrium equations of the network are linearized introducing given values of $q$ for all its members. The inputs of the FDM are: the coordinates of the fixed nodes (supports), the force-length ratio of each member, the connectivity between the nodes and the external forces. Other form-findings methods can be seen in [04].

Topological Mapping (TM) introduced by Hernández-Montes et al. [05,06] is a mapping method that generate a network based on a set of topological rules defined by the designer. An initial geometrical guess of the final equilibrium form of the network is needed to start the form-finding procedure if TM is not included in FDM (TMFDM $[01-03,05,06])$.

Compression structures can be designed using TM-FDM as pin-jointed networks with all its members in compression. FDM was initially conceived for the design of tension structures, being its self-weight negligible. However, the self-weight of compression structures cannot be ignored. In Carbonell-Márquez et al. [07] the selfweight is introduced as external forces in FDM. By doing so the linearity of the equilibrium equations of FDM disappears because the weight of the structure depends on its final shape. The linearity of the equilibrium equations is restored following the iterative procedure proposed by Carbonell-Márquez et al. [07]. This procedure is inspired in the hanging models used by the famous Spanish architect Antonio Gaudí (18521956) [08]. The tension structure is computed using TM-FDM and the inverse is the compression-only form.

The designer assigns the force-length ratio value to each member of the network. Members with a high q carry a higher level of loads, working as ribs of the compression structure. The process of assignation of a q value to each member of the network is directly related with the final shape of the structure, largely because as it has been said previously the form-finding procedure carried out in TM-FDM is similar to the hanging chain models employed by Antonio Gaudí. The proper distribution of ribs in the mesh by the designer can result in aesthetical final shapes.

Here, a two-storey compression structure with inner ribs has been designed using TM-FDM. The ground floor has an asymmetrical plan view and it has a series of arches in the contour with 
a central hole that works as a skylight. The top floor also has an asymmetrical plan view and it is connected to the ground floor in four points.

\section{FORCE DENSITY METHOD}

The FDM is a method for networks analysis. The equilibrium of pin-jointed networks is solved by means of a single system of linear equations. Here, the same terminology as found in [02] is used. A general network is composed by nt nodes and $\mathrm{m}$ members or branches. The nodes that have fixed coordinates are called fixed nodes (acting as supports) and the others are called free nodes. The coordinates along the $x$, $y$ and $z$ directions of the nodes are collected in the following vectors: $x=\left[x_{1}, \ldots, x_{n}\right]^{\top}, y=\left[y_{1}\right.$, $\left.\ldots, y_{n}\right]^{\top}$ and $z=\left[z_{1}, \ldots, z_{n}\right]^{\top}$ for free nodes (being $n$ the total number of free nodes) and $x_{f}=$ $\left[x_{f 1}, \ldots, x_{n f}\right]^{\top}, y_{f}=\left[y_{f 1}, \ldots, y_{f n} f\right]^{\top}$ and $z_{f}=\left[z_{f 1}, \ldots\right.$, $\left.z_{\text {fnf }}\right]^{\top}$ for fixed nodes (being $n f$ the total number of fixed nodes). ( )T represents the transpose operation. The length li and the internal force si of each member are collected in the vectors $I=$ $\left[\mathrm{I}_{1}, \ldots, \mathrm{I}_{\mathrm{m}}\right]^{\top}$ and $\mathrm{s}=\left[\mathrm{s}_{1}, \ldots, \mathrm{s}_{\mathrm{m}}\right]^{\top}$ respectively. The

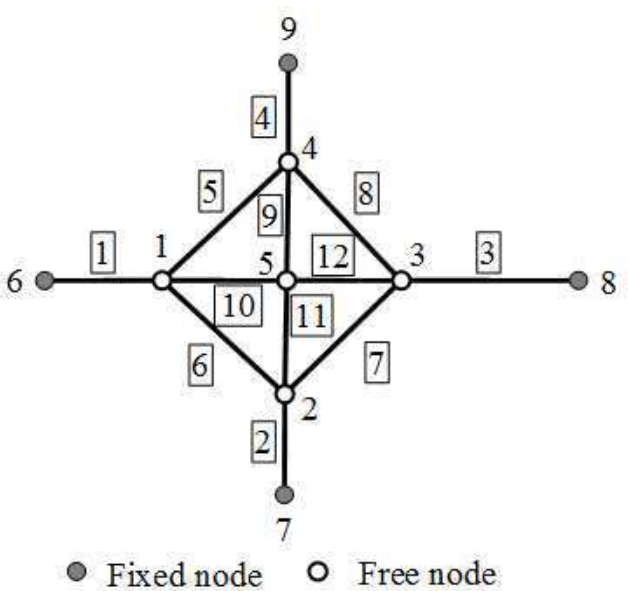

force-length ratio vector is defined as $q_{j}=s_{j} / I_{j}$ for each member of the mesh. All the $q$ values are collected in the vector $q=\left[q_{1}, \ldots, q_{m}\right]^{\top}$. Finally, vectors $P_{x}=\left[p_{1 x}, \ldots, p_{n t x}\right]^{\top}, P_{y}=\left[p_{1 y}, \ldots, p_{n t y}\right]^{\top}$ and $P_{z}=\left[p_{1 z}, \ldots, p_{n t z}\right]^{\top}$ collect the external forces applied in each node in each direction.

The connectivity matrix $C_{s}$ is a $m \times n t$ matrix that describes the connectivity between all the nodes of the mesh. It is constructed in the following way: if a member $j$ links the nodes $i(j)$ and $k(j)$, with $\mathrm{i}<\mathrm{k}$, the ith and kth elements of the jth row of $C S$ are set to 1 and -1 respectively:

$$
C_{s}(j, r)= \begin{cases}+1 \quad \text { if } i(j)=r \\ -1 \quad \text { if } k(j)=r \\ 0 \quad \text { for the rest }\end{cases}
$$

In the original method [02] the fixed nodes were taken at the end of the sequence, partitioning the connectivity matrix into two parts $\mathrm{CS}=[\mathrm{C}, \mathrm{Cf}]$. $\mathrm{C}\left(\mathrm{eR}^{\mathrm{m} \times \mathrm{n}}\right)$ and $\mathrm{Cf}\left(\mathrm{eR}^{\mathrm{m} \times \mathrm{n} f}\right)$ describe the connectivity between the free and fixed nodes respectively (see the example of Figure 1).

$$
\left.\begin{array}{ccccc:cccc}
1 & 0 & 0 & 0 & 0 & -1 & 0 & 0 & 0 \\
0 & 1 & 0 & 0 & 0 & 0 & -1 & 0 & 0 \\
0 & 0 & 1 & 0 & 0 & 0 & 0 & -1 & 0 \\
0 & 0 & 0 & 1 & 0 & 0 & 0 & 0 & -1 \\
1 & 0 & 0 & -1 & 0 & 0 & 0 & 0 & 0 \\
1 & -1 & 0 & 0 & 0 & 0 & 0 & 0 & 0 \\
0 & 1 & -1 & 0 & 0 & 0 & 0 & 0 & 0 \\
0 & 0 & 1 & -1 & 0 & 0 & 0 & 0 & 0 \\
0 & 0 & 0 & 1 & -1 & 0 & 0 & 0 & 0 \\
1 & 0 & 0 & 0 & -1 & 0 & 0 & 0 & 0 \\
0 & 1 & 0 & 0 & -1 & 0 & 0 & 0 & 0 \\
0 & 0 & 1 & 0 & -1 & 0 & 0 & 0 & 0
\end{array}\right)
$$

Figure 1: A two dimensional pin-jointed structure and its corresponding connectivity matrix CS [C, $\left.C_{f}\right]$. Adapted from [02]

The equilibrium equations of a general pin-jointed network (sum of all the forces applied in each node equal to zero) are the following:

$$
\begin{aligned}
& \mathbf{C}^{\mathrm{T}} \mathbf{Q C x}+\mathbf{C}^{\mathrm{T}} \mathbf{Q} \mathbf{C}_{\mathrm{f}} \mathbf{x}_{\mathrm{f}}+\mathbf{P}_{\mathbf{x}}=\mathbf{0} \\
& \mathbf{C}^{\mathrm{T}} \mathbf{Q C y}+\mathbf{C}^{\mathrm{T}} \mathbf{Q} \mathbf{C}_{\mathrm{f}} \mathbf{y}_{\mathrm{f}}+\mathbf{P}_{\mathrm{y}}=\mathbf{0} \\
& \mathbf{C}^{\mathrm{T}} \mathbf{Q C z}+\mathbf{C}^{\mathrm{T}} \mathbf{Q} \mathbf{C}_{\mathrm{f}} \mathbf{Z}_{\mathrm{f}}+\mathbf{P}_{\mathrm{z}}=\mathbf{0}
\end{aligned}
$$

Where $Q$ is the diagonal matrix of $q$.

\section{TOPOLOGICAL MAPPING}

One of the main inputs of FDM is the connectivity matrix C. Hernández-Montes et al. [05, 06] proposed a method called Topological Mapping (TM) to construct $C$. This method creates meshes of triangles based on topology without considering the final equilibrium position of the nodes. The inputs of TM are the number of steps $\mathrm{N}$, the number of nodes of the first step Nni, the type of network (open or closed) and the topological relation between consecutive steps. 
TM provides three different types of relation between consecutive steps: A, B and C. In all of them the nodes of a given step are connected with the adjacent ones (these members are called here step members). Besides that each node of a given step is connected with three, two or alternatively one or three nodes of the next step for types A, B and C respectively (these members are called here radial members). In a closed mesh the contour of the final shape corresponds to the nodes of the final step (see Figure 2 ). On the other hand, in an open mesh the contour of the topological mesh corresponds to the contour of the final shape (see Figure 2).

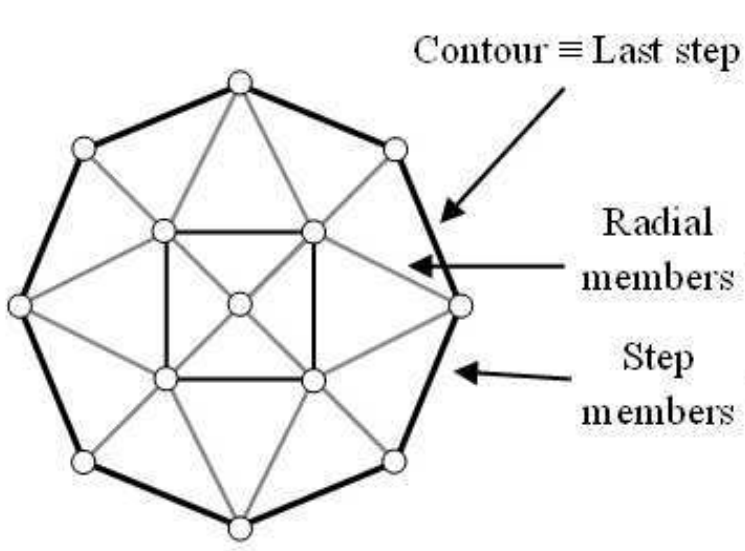

(a)

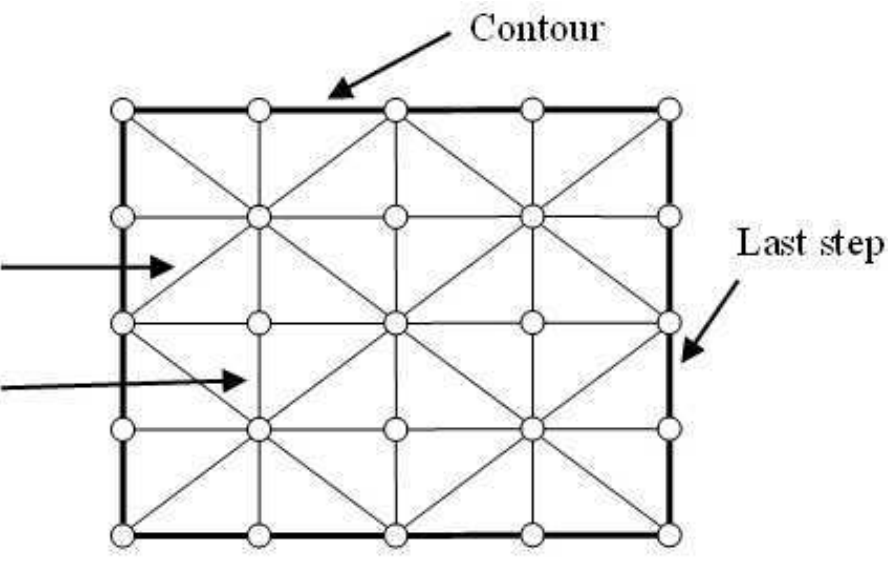

(b)

Figure 2: Types of meshes: closed (a) and open (b). Adapted from [07]

The topological relationships $A, B$ and $C$ can be combined forming a topological sequence (for example C-B-A-A). In a mesh of $\mathrm{N}$ steps the topological sequence must contain $\mathrm{N}-1$ letters $(A$, $B$ and $\mathrm{C})$.

\section{FORM-FINDING PROCEDURE}

The form finding procedure followed in this work is the proposed by Carbonell-Márquez et al. [07]. The self-weight vector $P_{z, w}=\left[p_{1 z, w}, \ldots, p_{n t z}, w\right]^{\top}$ is introduced in FDM in the $z$-direction:

$$
\left.\begin{array}{l}
\mathbf{C}^{\mathrm{T}} \mathbf{Q C x}+\mathbf{C}^{\mathrm{T}} \mathbf{Q} \mathbf{C}_{\mathrm{f}} \mathbf{x}_{\mathrm{f}}+\mathbf{P}_{\mathrm{x}}=\mathbf{0} \\
\mathbf{C}^{\mathrm{T}} \mathbf{Q C y}+\mathbf{C}^{\mathrm{T}} \mathbf{Q} \mathbf{C}_{\mathrm{f}} \mathbf{y}_{\mathrm{f}}+\mathbf{P}_{\mathrm{y}}=\mathbf{0} \\
\mathbf{C}^{\mathrm{T}} \mathbf{Q C z}+\mathbf{C}^{\mathrm{T}} \mathbf{Q} \mathbf{C}_{\mathrm{f}} \mathbf{z}_{\mathrm{f}}+\mathbf{P}_{z}+\mathbf{P}_{z, w}=\mathbf{0}
\end{array}\right\}
$$

This vector depends on the position of the nodes. The self-weight of the structure $y$ is expressed in force by units of area. The members that compose the ribs have a higher weight, so a linear self-weight expressed in force by units of length $\lambda$ is also defined. Finally, the component i of $P z, w$ is calculated as the summation of the half of the weight of every member that has node $i$ as vertex and is part of a rib and one third of the weight of every triangle that contains the node $i$ as vertex.
The system of equations shown in Equation 3 is not linear due to $P_{z, w}$. Despite this, the equilibrium equations are solved linearly by iterations [07].

\section{TWO-STOREY COMPRESSION STRUCTURE WITH INNER RIBS}

A two storey compression structure with inner ribs has been computed following the procedure proposed by Carbonell-Márquez et al. [07]. For both ground and upper floors $\gamma=1 \mathrm{kN} / \mathrm{m}^{2}$ and $\lambda$ $=1 \mathrm{kN} / \mathrm{m}$.

The ground floor is an open mesh with a central hole that works as a skylight. The open mesh has 51 steps $(N=51)$ and the initial step has 50 nodes $(\mathrm{Nni}=50)$. Type $\mathrm{C}$ has been used for all the steps because for this type of relationship the number of nodes of each step remains constant (in the others the number of nodes increases from a step to the next). This means that the topological sequence is $\mathrm{C}$...C with a total of $50 \mathrm{C}$. The coordinates of the fixed nodes (supports) are listed in Table 1. The final equilibrium form of the mesh of the ground floor is shown in Figure 3 together with the $q$ vector used (distribution of ribs). This final shape of the ground floor has not been computed separately from the upper part: the whole structure is computed together, but for a better viewing of the ground floor it has been shown isolated. 
Table 1: Fixed coordinates of the ground floor

\begin{tabular}{|c|c|c|c|}
\hline & $x(m)$ & $y(m)$ & $z(m)$ \\
\hline 1 & 2,31 & 3,26 & 0,00 \\
\hline 2 & 3,76 & 1,81 & 0,00 \\
\hline 3 & 6,00 & 0,80 & 0,00 \\
\hline 4 & 7,96 & 0,71 & 0,00 \\
\hline 5 & 9,43 & 1,27 & 0,00 \\
\hline 6 & 2,23 & 4,68 & 0,00 \\
\hline 7 & 3,79 & 5,19 & 0,00 \\
\hline 8 & 5,99 & 5,72 & 0,00 \\
\hline 9 & 8,19 & 4,36 & 0,00 \\
\hline 10 & 9,52 & 2,57 & 0,00 \\
\hline
\end{tabular}

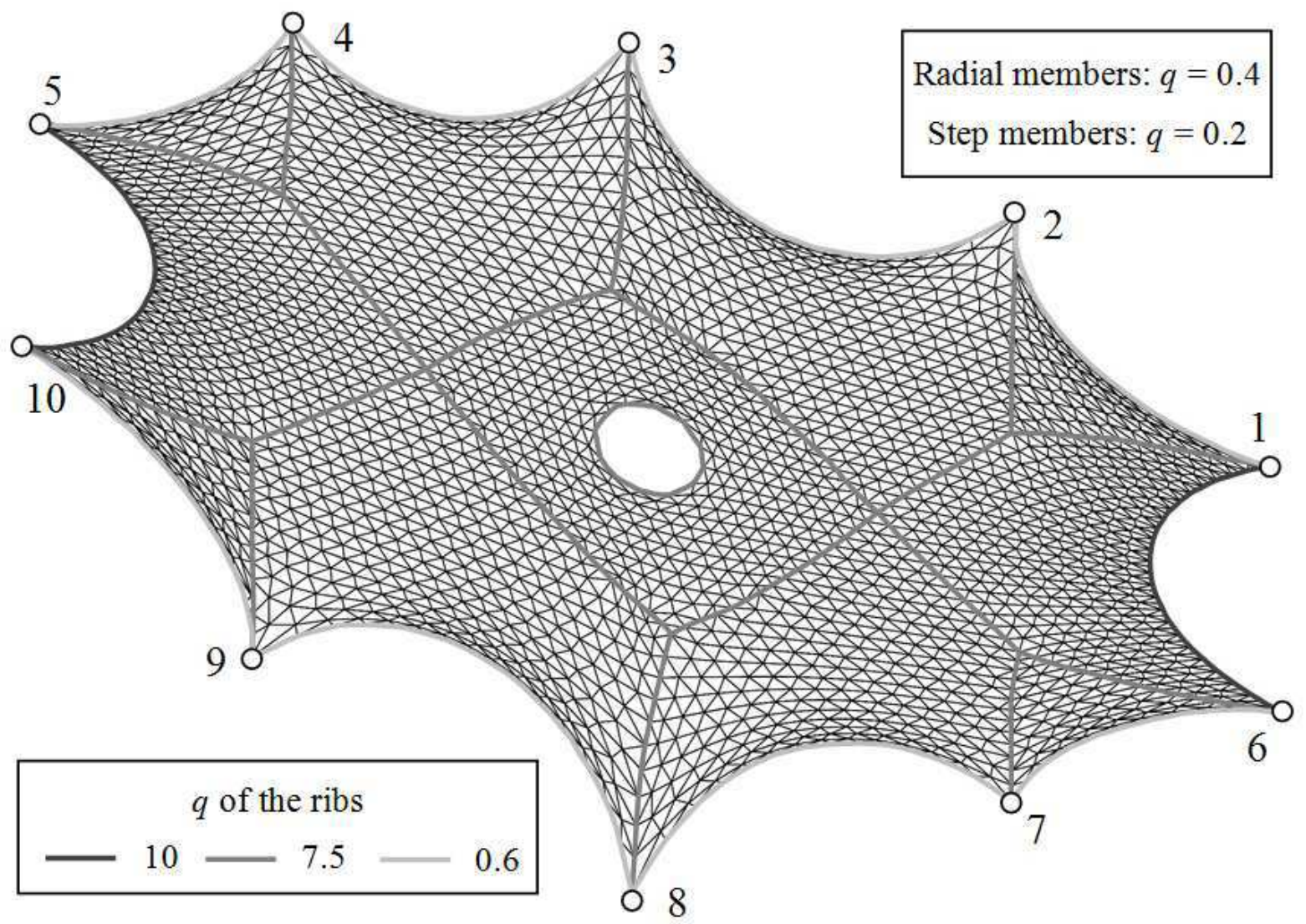

$$
\mathbf{q}=[\underbrace{q_{1}, q_{2} \ldots q_{i}}_{\text {Contour }}, \underbrace{q_{i+1}, q_{i+2} \ldots q_{j}}_{\text {Ribs }}, \underbrace{q_{j+1}, q_{j+2} \ldots q_{k}}_{\text {Hole }}, \underbrace{q_{k+1}, q_{k+2} \ldots q}_{\begin{array}{c}
\text { Radial } \\
\text { members }
\end{array}}, \ldots, \underbrace{q_{m}, q_{m+1} \ldots q_{50}}_{\begin{array}{c}
\text { Step } \\
\text { members }
\end{array}}]
$$

Figure 3: Final equilibrium form of the ground floor mesh and distribution of the ribs

On the other hand the upper floor is a closed mesh with 11 steps. The initial step has 32 nodes and type $B$ has been used for all the steps (the topological sequence is $B$...B with a total of 10 $B)$. This part of the structure has not fixed nodes; it has four connections (nodes in common) with the ground floor. The final equilibrium form of the mesh of the upper floor is shown in Figure 4 together with the q vector used.

Figures 5 and 6 show different views of the final equilibrium form of the whole structure. Ribs have been highlighted in order to better understand the structural behaviour of the final shape. 


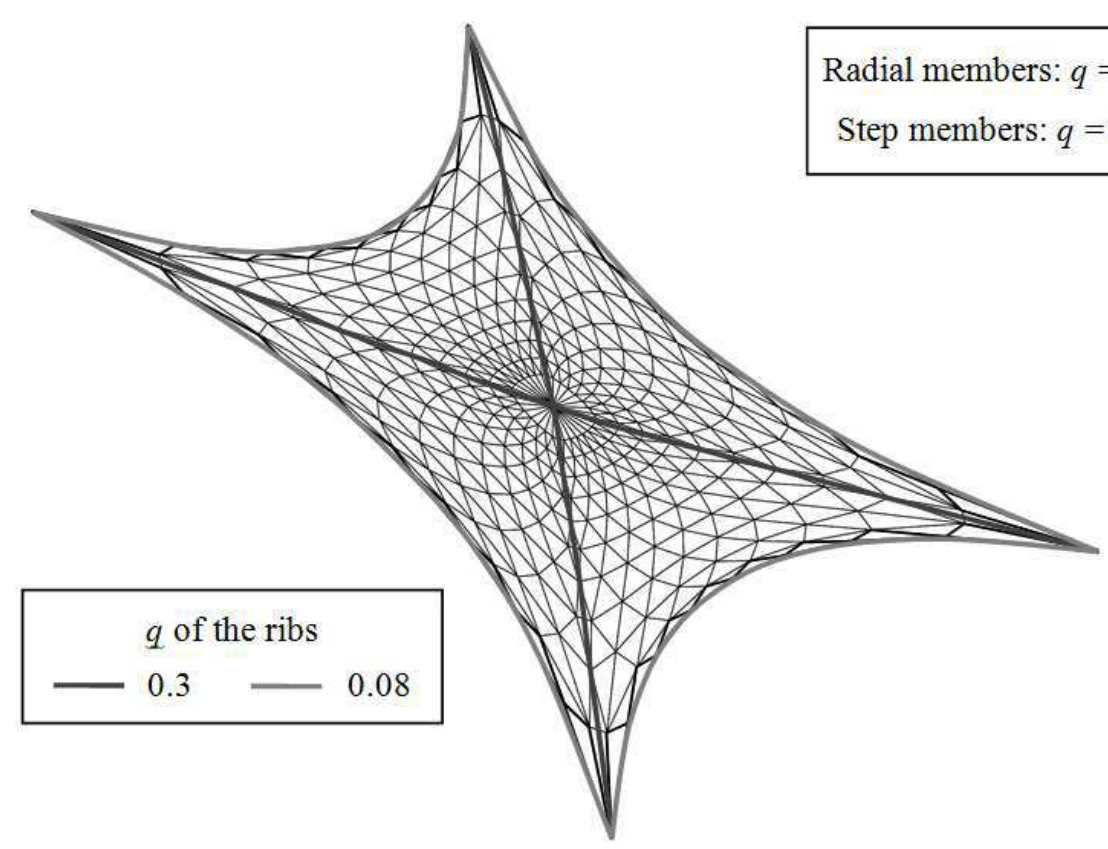

$$
\mathbf{q}=[\underbrace{q_{1}, q_{2} \ldots q_{i}}_{\text {Contour }}, \underbrace{q_{i+1}, q_{i+2} \ldots q_{j}}_{\text {Ribs }}, \underbrace{q_{j+1}, q_{j+2} \ldots q_{k}}_{\begin{array}{c}
\text { Radial } \\
\text { members }
\end{array}}, \underbrace{\left.q_{m}, q_{m+1} \ldots q_{50}\right]}_{\begin{array}{c}
\text { Step } \\
\text { members }
\end{array}}
$$

Figure 4: Final equilibrium form of the upper floor mesh and distribution of the ribs
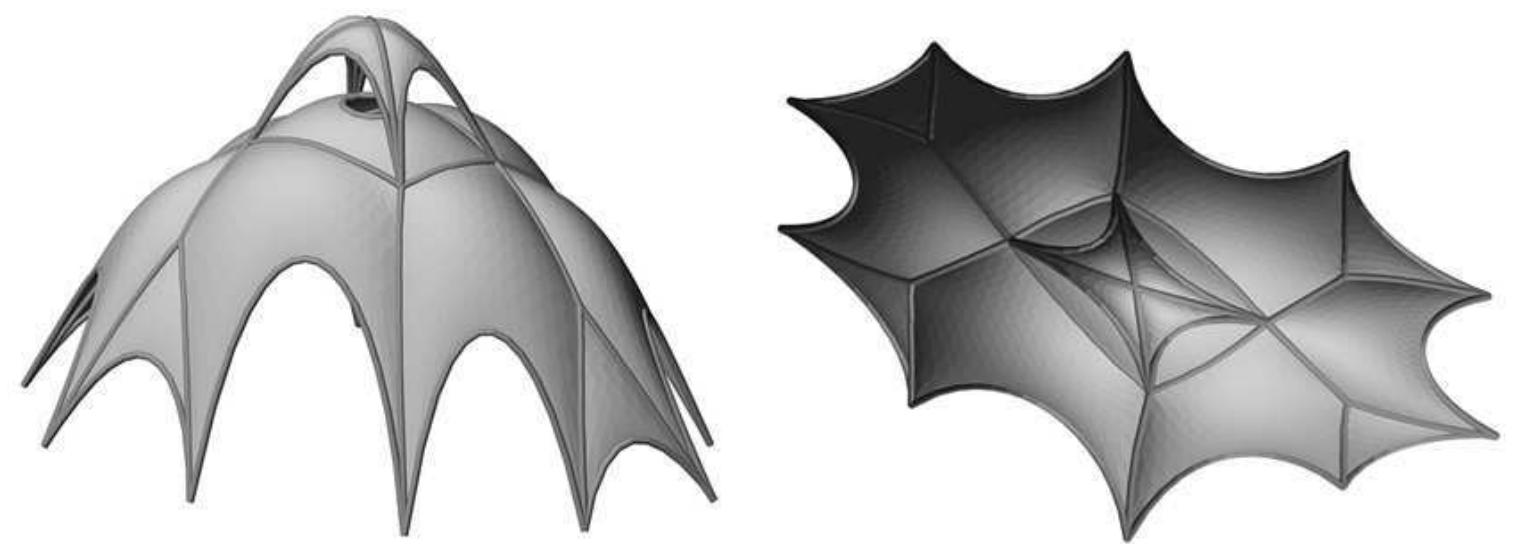

Figure 5: Two-storey compression structure computed using TM-FDM: general (left) and plan (right) views
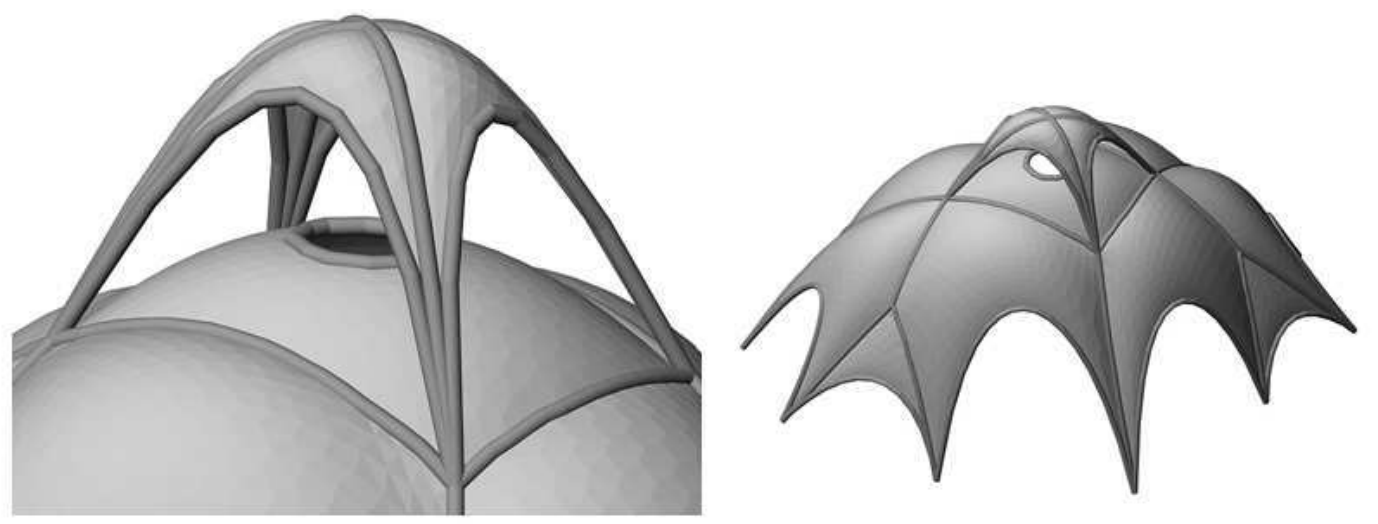

Figure 6: Two-storey compression structure computed using TM-FDM: detail of the upper floor (left) and a general view of the skylight (right) 


\section{CONCLUSION}

The iterative TM-FDM form-finding procedure proposed by Carbonell-Márquez et al. [07] is a powerful tool for the design of compression structures. Inner ribs can be defined as members with a high force-length ratio. A complex two-storey compression structure with inner ribs has been designed. It presents a combination of closed (ground floor) and open meshes (upper floor). In addition to this, the ground floor has a skylight, highlighting the design flexibility of TM-FDM.

\section{REFERENCES}

1) K. Linkwitz, H.J. Schek, Einige Bemerkungen zur Berechnung von vorgespannten Seilnetzkonstruktionen, Ingenieur-Archiv. 40 (1971) 145-158.

2) H.J. Schek, The force density method for form-finding and computation of general networks, Comput. Methods Appl. Mech. Eng. 3 (1974) 115-134.

3) K. Linkwitz, About form-finding of doublecurved structures, Eng. Struct. 21 (1999) 709-718.

4) D. Veenendaal, P. Block, An overview and comparison of structural form finding methods for general networks, Int. J. Solids Struct. 49 (2012) 3741-3753. doi:10.1016/ j.ijsolstr.2012.08.008.

5) E. Hernández-Montes, R. Jurado-Piña, E. Bayo, Topological Mapping for Tension Structures, J. Struct. Eng. 132 (2006) 970-977.

6) R. Jurado-Piña, L.M. Gil-Martín, E. Hernández-Montes, Topological mesh for shell structures, Appl. Math. Model. 33 (2009) 948-958. doi:10.1016/j.apm.2007.12.018.

7) J.F. Carbonell-Márquez, L.M. Gil-Martín, M.A. Fernández-Ruiz, E. Hernández-Montes, Topological design of compression structures, Arch. Appl. Mech. (2015).

8) S. Huerta, Structural design in the work of Gaudí, Archit. Sci. Rev. 49 (2006) 324-339.

Paper sent to revision: 04.02.2016.

Paper ready for publication: 07.03.2016. 


\section{PROJEKTOVANJE KOMPRESIONE STRUKTURE SA UNUTRAŠNJIM REBRIMA} KORIŠĆENJEM METODE SNAGE GUSTINE I TOPOLOŠKOG MAPIRANJA

Manuel Alejandro Fernández Ruiz, Univerzitet u Granadi, Granada, Španija Luisa Maria Gil-Martin, Univerzitet u Granadi, Granada, Španija

Struktura samo sa kompresijom može da se modelira kao pin-spojena mreža sa svim članovima u kompresiji. Konačni oblik mreže se može izračunati korišćenjem metode snage gustine (FDM) zajedno sa toploškim mapiranjem (TM), uvođenje sopstvene težine iterativno dok se ne pronađe ravnoteža. Jedan od ulaznih parametara FDM je sila-dužina odnos K svakog člana mreže. Članovi sa visokim $k$ nose veći stepen opterećenja, radi kao rebro strukture. Projektant definiše adekvatnu raspodelu rebara u mreži, što dovodi do estetskih krajnjih oblika. Evo, dvospratna kompresija struktura sa unutrašnjim rebrima je dizajniran pomoću TM-FDM.

Ključne reči: Kompresiona struktura, Metod Snage gustine, Topološko mapiranje, Oblik-nalaz 